\title{
Design of a Low Energy Consumption Office Building using Dynamic Simulations
}

\author{
Tiberiu Catalina ${ }^{1}$, Guillaume Menegaldo ${ }^{1}$, Catalin Lungu ${ }^{1}$, Valentin Gavan $^{2}$, Gheorghe Ilisei ${ }^{1}$ \\ ${ }^{1}$ Technical University of Civil Engineering, Bucharest, ROMANIA \\ ${ }^{2}$ ENGIE Lab, Research \& Technologies Division, Center for Research and Innovation in \\ NaturalGas and New Energies (CRIGEN), Paris, FRANCE
}

\begin{abstract}
Among the building's categories, office buildings are one of the largest consumers for heating and cooling the indoor space. Within this article it is shown that with the right architectural and engineering design it is possible to build a low energy consumption office building. The building under study consists of a basement, a ground floor, 5 identical floors and a 6th floor, overlooking a partially converted terraced roof. The south-east facing façade is configured as a "Trombe wall" (for energy efficiency purposes) and the whole building is crossed by a greenhouse, also to reduce energy demand during winter season. We have 3D modelled the entire building under Design Builder and we have run simulations with a time step of $1 / 2$ hour. Along with the "Trombe wall" and the greenhouse the building is equipped with a field of photovoltaics for electric production and a green roof. The buildings itself is very well insulated, the windows are triple glazed and represent $70 \%$ of the walls' total surface. To reduce the cooling demand, the windows are equipped with automatic external blinds that close themselves when the solar irradiation is higher than $120 \mathrm{~W} / \mathrm{m}^{2}$. The final annual building demand is $32,725.28 \mathrm{kWh}$ for heating and $64299.55 \mathrm{kWh}$ for air conditioning. By bringing it to the net conditioned area of the building $\left(2645.72 \mathrm{~m}^{2}\right)$, final demand is worth $36.7 \mathrm{~kW} / \mathrm{m}^{2} /$ year which makes this building a highly efficient one. The article originality arises from the architecture of the studied building mixed with passive and active solutions to achieve low energy consumption and high indoor comfort.
\end{abstract}

\section{Introduction}

Improving the energy efficiency of office buildings is a major challenge to achieve the goal of reducing greenhouse gas emissions by 2050 . For this important task, all the European Union countries established national energy plans for rehabilitation or construction of new projects leading with sets of technical solutions, methods and procedures relating to envelope components, climate systems, architecture, energy management and environmental impacts to achieve buildings with a high level of energy performance and indoor comfort. During the last decades many research articles were published on this topic. Guang et. al (2016) have developed a novel method to predict the energy consumption of an office building. Their study was validated with different topologies of buildings. Rui et al. (2017) have established a building energy database for 30 Hong Kong office buildings and have predicted the energy consumption using two modelling techniques. A Brazil team of researchers Veloso et al. (2017) were focused on the analysis of architectural elements (type of glass, window to wall ratio, average absorptance of walls, existence of solar protection) of 102 office buildings. 27 office buildings were analyzed based on their energy bills by $\mathrm{Lu}$ et al. (2016) and found using multiple linear regression analysis the significant impact factors on the energy demand. Using dynamic simulations Gustafsson et al. (2016) have assessed the energy renovation measures for multiple European office buildings. They have found that photovoltaic system can reduce the environmental impact. Analyzing three different office building typologies Alves et al. (2016) has calculated the energy consumption and calculated the Energy Use Intensity. Using dynamic simulations in order to predict the retrofit measures for an office building was the work the Ko et al. (2016).

Nomura et Hiyama (2017), in their review article, stated that natural ventilation is an effective way for reducing the energy consumption. Neves and Marques (2017) have analyzed 40 office buildings in Sao Paulo City, Brazil using computer simulations with the EnergyPlus engine. They have presented several important parameters for the envelope to have a low energy building.

The goal of this article is to propose an office building architecture prototype and to model it in 3D in order to perform various dynamic simulations of the energy performance and comfort, to help the design approach as much as possible to the status of "Low Energy Building". Another objective is to show that with correct design measures and tools we can achieve high-tech energy efficient buildings.

\section{Office building architecture and its bioclimatic solutions}

The building under study consists of a basement, a ground floor, 5 floors Identical and a 6th floor smaller, overlooking a green roof partly done up on terrace. The south-east facing façade is configured as a 'Trombe wall" and the whole building is crossed by a greenhouse in the middle. The basement consists of a large room containing the technical equipment of the building, as well as stairwells and elevator to access it. The ground floor consists of a circular glass entrance with a revolving door (zone 1), a large lobby (zone 5), a large amphitheater (zone 2), a staircase (zone 4) and an elevator shaft (zone 3 ) - see Figure 2 c). The floors $R+1$ to $R+5$ contain a 
staircase (zone 5), an elevator shaft (zone 2), a corridor (zone 7), two offices (zones 3 and 1) 6) and toilets (zone $4)$. The $R+6$ consists of a staircase (zone 2 ), an elevator shaft (zone 3), a corridor (zone 5), an amphitheater (zone 1) An office (zone 6) and toilets (zone 4). The "Trombe wall" is also modeled by a single block containing a single zone, and it is adjacent to the ground floor and the floors $\mathrm{R}+1$ to $\mathrm{R}+5$. Each level is equipped with two rows of vents (one under the ceiling and one above the floor). In addition, a field of photovoltaic panels is positioned on the terrace roof of the $\mathrm{R}+6$ and a part of the roof terrace of the $\mathrm{R}+5$ is arranged in vegetal roofing.

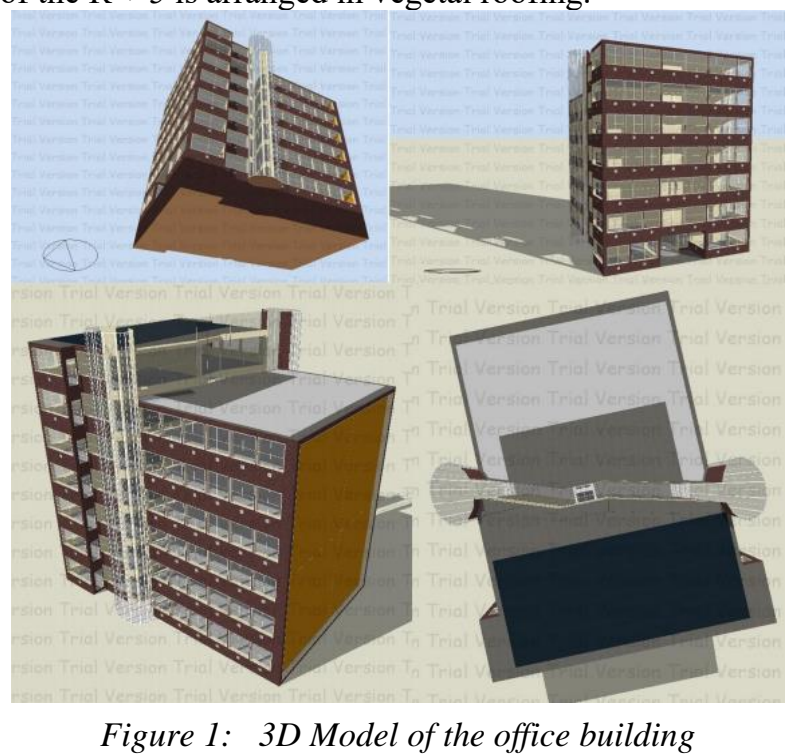

The building was proposed by a team of architects from Bucharest, ROMANIA in order to be an example of sustainable and correct bioclimatic solutions applied to office buildings. The whole project was realized with an interdisciplinary team of architects, engineers and energy advisors. The building has a very good insulation level: for the external walls the U-value $=0.251 \mathrm{~W} / \mathrm{m}^{2} \mathrm{~K}$, for the internal walls the $\mathrm{U}$-value $=2.378 \mathrm{~W} / \mathrm{m}^{2} \mathrm{~K}$, for the ground floor the $\mathrm{U}-$ Value $=0.176 \mathrm{~W} / \mathrm{m}^{2} \mathrm{~K}$ and for the roof the Uvalue $=0.186 \mathrm{~W} / \mathrm{m}^{2} \mathrm{~K}$. For the openings, the building is equipped with triple glazed windows filled with an argon layer. The glazing total solar transmission (SHGC) is 0.47, the light transmission 0.661 and the $\mathrm{U}$-value calculated based on ISO $10292 / \mathrm{EN} 673$ is $0.786 \mathrm{~W} / \mathrm{m}^{2} \mathrm{~K}$. The windows represent $70 \%$ of the surface of the walls and have a height of $2 \mathrm{~m}$ and are spaced $2 \mathrm{~m}$ apart. They are equipped with closed external blinds when the radiation of the sun is more than $120 \mathrm{~W} / \mathrm{m}^{2}$ during air conditioning and at night to limit thermal losses by radiation. In fact, many researchers found this solution among the best one in order to reduce the solar heat gains Bustamante et al. (2017). Ventilation grilles are positioned under each window. $5 \%$ of the window area can be opened during building occupancy periods to increase the building's natural ventilation. The greenhouse is equipped with double-glazed windows with air gap on the outer walls, and $100 \%$ of the exterior surface is glazed. The internal walls are equipped with double-glazed internal windows over their entire surface to heat the adjoining rooms during winter period. The "Trombe wall" consists of an inner wall, a $10.5 \mathrm{~cm}$ air blade, and an outer pane. The inner wall consists of a concrete layer of high thermal inertia with a thin layer of copper treated with emissivity on the outer surface with a high solar absorbance. The glass is the same as for the exterior walls of the greenhouse, except that it is equipped with external blinds closed during the days if the air conditioning is on and high solar radiation in order to avoid summer overheating. The vegetal roofing takes up the composition of the roof of the building by adding a layer of vegetated earth.

It can be noticed that we have applied several passive measures in order to reduce energy consumption of the building:

- Trombe wall - to reduce cooling demand

- Greenhouse - to reduce heating demand and to increase the indoor illuminance levels for a perfect visual comfort inside the building

- Green roof - to decrease the solar radiation heat gains

- Very good insulation of the envelope - to reduce cooling/heating demand

- External blinds - to decrease the solar radiation heat gains

- Natural ventilation to be used in certain periods of the year

\section{Simulation results and optimization of the building}

For the building simulations the DesignBuilder software was used. DesignBuilder is a thermal simulation software for buildings with a dedicated modeling module. It is addressed to both architects and engineers and makes it possible to optimize and evaluate various configurations envisaged in terms of architecture or technical solutions (insulation, equipment, etc.). The model simulation data defines the start and end dates of the simulation, the time step, the temperature control mode, the solar radiation calculation parameters, and the advanced algorithm parameters. For this study, multiple simulations were done on a full year with a time step of 30 minutes. It was considered in the software the module "3-Full interior and exterior" solar distribution to take into account the radiation inputs through the greenhouse. As for the "Trombe wall", the model "5-Cavity" algorithm was used for the calculation of internal convection coefficients. As it can been seen from Figure 2, the building architecture was correctly translated in a 3D Model under Design Builder module and the greenhouse inside the building was also modeled as a separate thermal zone. 


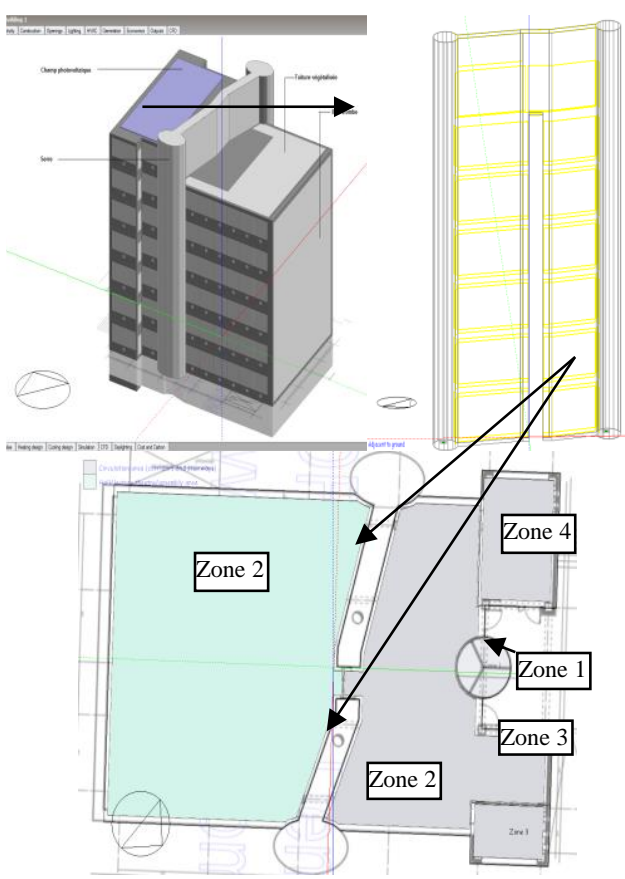

Figure 2: a) Design Builder 3D Model b) Greenhouse c) Ground floor thermal zones

The activity parameters determine the zone types and group the scenarios like: occupancy, internal heat gain, fresh air requirements, heating and cooling temperature set points, temperature $\log$ s for natural ventilation and domestic hot water demand. The traffic areas include corridors, staircases and elevators and hall entrance. These zones are not occupied for long periods and have therefore a relatively low heating temperature set point $\left(15^{\circ} \mathrm{C}\right)$. The minimum temperature set point for natural ventilation is $21^{\circ} \mathrm{C}$. Below this temperature, the vents and exterior windows will be closed. Offices have a wider range of heating and cooling $\left(21^{\circ} \mathrm{C}\right.$-heating and $24^{\circ} \mathrm{C}$ cooling) to ensure a good level of thermal comfort in these areas. The minimum temperature set point for the natural ventilation is $23^{\circ} \mathrm{C}$, or $2^{\circ} \mathrm{C}$ above the temperature set point of heating to prevent simultaneous heating and fresh air natural ventilation. All areas will be equipped with standard terminal units.

The entire air flow required for heating and cooling is composed of outside air (previously heated or cooled in an air handling unit (AHU) and a minimum required air flow is calculated to ensure an air change rate as a function of occupation. A recovery system for heat recovery is installed, with a high heat recovery rate of $70 \%$. For the heating system we have considered a highperformance low-temperature boiler. For the air conditioning system, a heat pump with a COP of 5.5 is used. Natural ventilation will be preferred and when this is not able to maintain good indoor thermal comfort than the air conditioning is used. The basement is neither heated nor conditioned, but it is naturally ventilated to ensure air renewal in the room. The greenhouse is mechanically ventilated at 10 air change rate/hour (ach) in summer to avoid overheating. The simulations were carried out for Bucharest climate and access to different meteorological values was possible.
For example, in Figure 3 it can be noticed that during the period of 15-21 July the outdoor maximum air temperature is around $34.8^{\circ} \mathrm{C}$ while minimum values are below $15^{\circ} \mathrm{C}$. The wind speed values are between 0 to 7 $\mathrm{m} / \mathrm{s}$ while the maximum solar direct radiation is 0.8 $\mathrm{kW} / \mathrm{m}^{2}$ while the diffuse part is $0.18 \mathrm{~kW} / \mathrm{m}^{2}$.

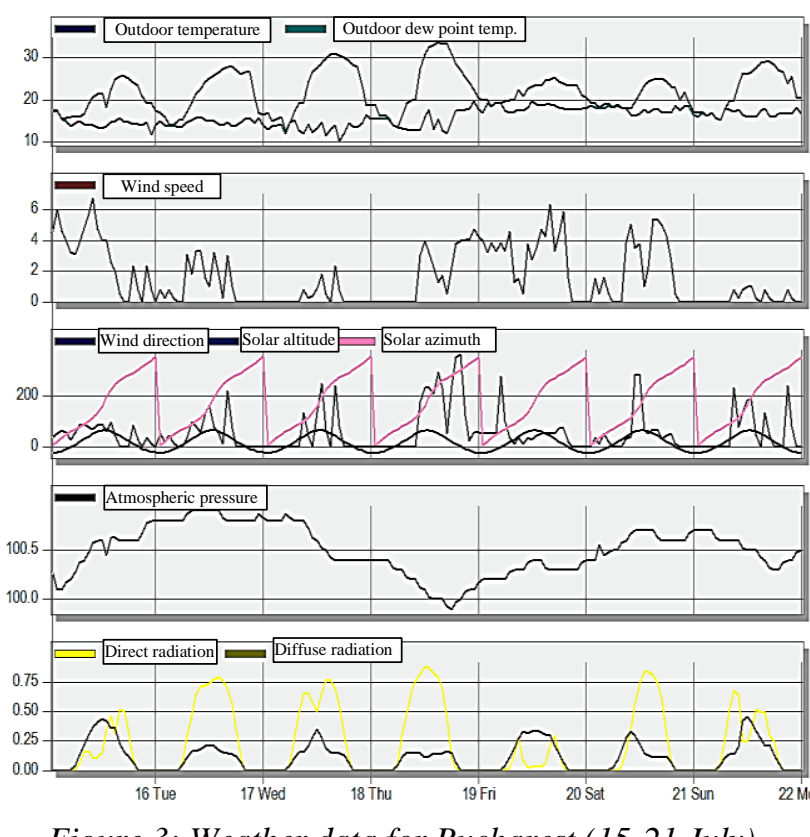

Figure 3: Weather data for Bucharest (15-21 July)

The simulation time calculation was more than 10 hours using a $73.2 \mathrm{GHz}$ CPU, 8 Gb Ram Personal Computer. As concerns the cooling and electric energy consumption it can be notice that maximum values are $185 \mathrm{~kW}$ (cooling) and $110 \mathrm{~kW}$ (electric consumption). These values are maximum during the summer period. For certain periods a heat recovery was possible.

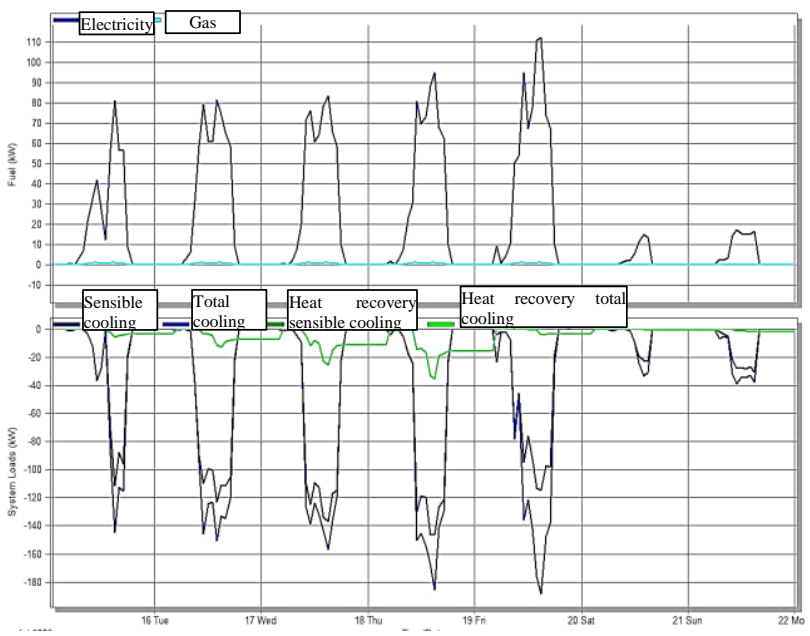

Figure 4: Cooling and electricity demand of the building during 15-21 July

As concerns the thermal comfort, we have characterized it using the operative temperature which is the mean temperature between the air temperature (aprox. $24{ }^{\circ} \mathrm{C}$ ) and the radiant temperature $\left(26^{\circ} \mathrm{C}\right)$ of the zones. The relative humidity in most of the cases is around $50 \%$ (optimal humidity) except certain hours when the values go up to $70 \%$. The thermal comfort achievement during 
summer season was also measured using the PMV index ( -3 very cold / -0.5 to 0.5 optimal / +3 very hot) and it can be observed from Figure 5 that the PMV values are below +0.5 and higher than 0 in most of the cases, except the end of the week and during weekend.

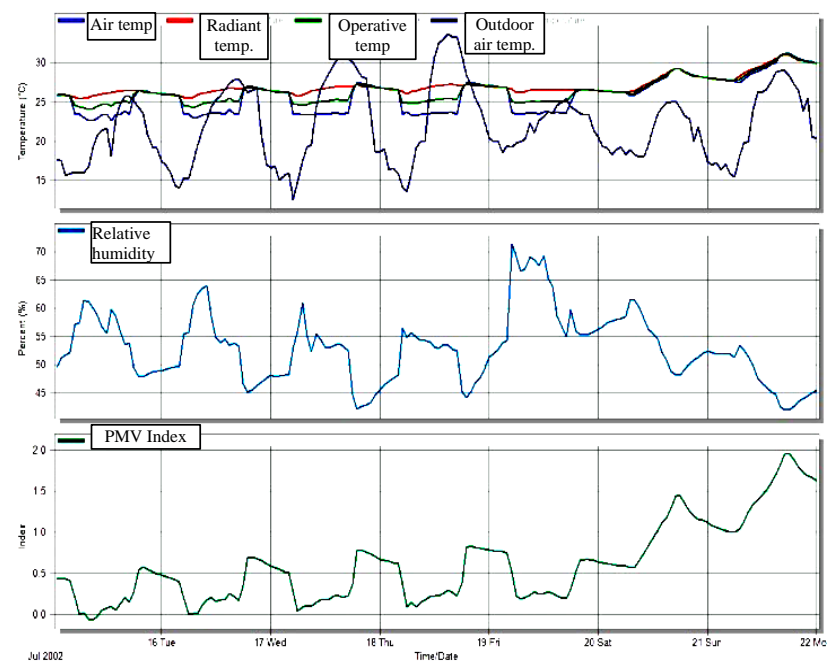

Figure 5: Different parameters for the assessment indoor thermal comfort (15-21 July)

The final annual building demand is $32,725.28 \mathrm{kWh}$ for heating and $64299.55 \mathrm{kWh}$ for air conditioning. By bringing it to the net conditioned area of the building $\left(2645.72 \mathrm{~m}^{2}\right)$, final demand is $36.7 \mathrm{kWh} / \mathrm{m}^{2} /$ year. Heating is provided by natural gas, while air conditioning is provided by electricity. Primary energy consumption is calculated by applying the factors for gas and electricity: 3,167 for electricity and 1,084 for gas. Therefore, the building has a primary energy consumption of 90.4 $\mathrm{kWh} / \mathrm{m}^{2} /$ year of primary energy. For $\mathrm{CO}_{2}$ emissions we apply the Romanian emission factors to the final energy consumption: $0.205 \mathrm{kgCO}_{2} / \mathrm{kWh}$ for gas and $0.09 \mathrm{kgCO}_{2}$ $\mathrm{kWh}$ for electricity. This gives the total $\mathrm{CO}_{2}$ emissions of $4.72 \mathrm{kgCO}_{2} / \mathrm{m}^{2} /$ year. The photovoltaic potential in Bucharest is substantially equivalent to that of the south of France. We will therefore favor the production of photovoltaic energy by placing on the roof of the $6^{\text {th }}$ floor a surface of $112.83 \mathrm{~m}^{2}$ of monocrystalline photovoltaic panels. The PV-array generates $18622.75 \mathrm{kWh}$ of electricity this representing almost $15 \%$ of the total electricity consumption of the building (heat pump, fans, pumps, interior lighting, internal equipment) and $25 \%$ of electricity consumption of air conditioning.

\section{Conclusions}

The building simulation optimized the building's energy consumption, thermal comfort and natural lighting by considering the characteristics of building materials, the passive and active solutions including heating/cooling/natural ventilation strategies for different areas. The building achieved thermal comfort in most of the cases. During the hottest summer week, the values of thermal comfort index PMV were slightly higher than +0.5 , while the operative temperature was at $25^{\circ} \mathrm{C}$. The building has an annual consumption of 12.37 $\mathrm{kWh} / \mathrm{m}^{2} /$ year of natural gas for heating and 24.67
$\mathrm{kWh} / \mathrm{m}^{2} /$ year of electricity for air conditioning. The building thus has an energy performance ratio of 0.88 , which allows it to be classified at the "Exceptional" level using the BREEAM Energy Scale. The total consumption of the building (heating, air conditioning, interior lighting, interior fittings, fans, pumps, domestic hot water) amounts to $65.21 \mathrm{kWh} / \mathrm{m}^{2} /$ year final energy. Within this article was presented an original architecture of an office building including a greenhouse and a ,'Trombe wall". Using numerical simulations, it was shown that the passive and active proposed solutions during design stage are valid and have a tremendous impact on the building energy balance.

\section{Acknowledgments}

We hereby acknowledge the "Asociatia Inginerie de Instalati Filiala Valahia" for their support with the design of the analyzed office building.

The research article is supported by the project ID P_37_229, SMIS 103427, Contract Nr. 22/01.09.2016, with the title „Smart Systems for Public Safety through Control and Mitigation of Residential Radon linked with Energy Efficiency Optimization of Buildings in Romanian Major Urban Agglomerations SMART-RADEN" supported by the Competitiveness Operational Program 2014-2020, POC-A.1- A.1.1.4 -E- 2015 competition.

\section{References}

Alves, T., Machado L., Gonçalves de Souza R. and P. de Wilde (2017), A methodology for estimating office building energy use baselines by means of land use legislation and reference buildings, Energy and Buildings, Volume 143, 15 May 2017, Pages 100-113.

Bustamante W., Uribe D.,Vera S., Molina G. (2017), An integrated thermal and lighting simulation tool to support the design process of complex fenestration systems for office buildings, Applied Energy, Volume 198, 15 July 2017, Pages 36-48.

Guang, S., Derong L. and Q. Weia (2016), Energy consumption prediction of office buildings based on echo state networks, Neurocomputing, Volume 216, 5 December 2016, Pages 478-488.

Gustafsson, M., Dipasquale C., Poppi S., Alessandro Bellini, Fedrizzi R., Bales C., Ochs F., Sié M. and S. Holmberg (2017), Economic and environmental analysis of energy renovation packages for European office buildings, Energy and Buildings, Available online 4 May 2017.

Jong-Hwan, Ko., Dong-Seok K. and J. Huh (2017), Baseline building energy modeling of cluster inverse model by using daily energy consumption in office buildings, Energy and Buildings, Volume 140, 1 April 2017, Pages 317-323.

Lu, S., Zheng S. and X. Kong (2016), The performance and analysis of office building energy consumption in the west of Inner Mongolia Autonomous Region, China, Energy and Buildings, Volume 127.

Neves L.O and T. H. Marques (2017), Building Envelope Energy Performance of High-rise Office buildings in 
Sao Paulo City, Brazil, Procedia Environmental Sciences, Volume 38, 2017, Pages 821-829.

Nomura M., and K. Hiyama (2017), A review: Natural ventilation performance of office buildings in Japan, Renewable and Sustainable Energy Reviews, Volume 74, July 2017, Pages 746-754.

Rui, J., Meng W., Ruoxi Z., Ning L. and Y. Zhao (2017), A study on energy performance of 30 commercial office buildings in Hong Kong, Energy and Buildings Volume 144, 1 June 2017, Pages 117-128.
Veloso A.C.V, Gonçalves de Souzab R.V. and RNicolau Nassar Koury (2017), Research of Design Features that Influence Energy Consumption in Office Buildings in Belo Horizonte, Brazil, Energy Procedia, Volume 111, March 2017, Pages 101-110. 